\title{
DESIGN AND SIMULATION OF A CYLINDER HEAD STRUCTURE FOR A COMPRESSED NATURAL GAS DIRECT INJECTION ENGINE
}

\author{
A. Shamsudeen ${ }^{1 *}$, S. Abdullah ${ }^{1,2}$, A.K. Ariffin ${ }^{1,2}$ M.R.M. Rasani ${ }^{1,2}$ and Y. Ali ${ }^{3}$ \\ ${ }^{1}$ Centre for Automotive Research, Faculty of Engineering and Built Environment \\ University Kebangsaan Malaysia, 43600 Bangi Selangor, Malaysia \\ Phone: +60389216454; Fax: +60389118314 \\ *Email: azhari@eng.ukm.my \\ ${ }^{2}$ Department of Mechanical and Materials Engineering, Faculty of Engineering \\ and Built Environment, University Kebangsaan Malaysia, \\ 43600 Bangi Selangor, Malaysia \\ ${ }^{3}$ Faculty of Mechanical Engineering, University Malaysia Pahang \\ 26600 Pekan, Pahang, Malaysia
}

\begin{abstract}
In this work, the design and simulation of a cylinder head with compressed natural gas direct injection (CNGDI) is studied based on finite element analysis. The analysis was carried out to simulate the stress and displacement for the cylinder head at various engine speeds in the range of between 1000 and $5400 \mathrm{rpm}$. The design is developed using CATIA V5, and simulated using MSC Nastran, then pre- and post-processed by MSC Patran. Based on the simulation results, an improved design for the CNGDI cylinder head was achieved. The stress and displacement analysis highlighted several areas of interest, and the maximum stress for the modified model of $56.16 \mathrm{MPa}$ was found not to exceed the allowable compressive yield strength of the material used (aluminum alloy A356-T6), of $172 \mathrm{MPa}$. The maximum displacement for the modified model, which was $0.00972 \mathrm{~mm}$, was below the lowest displacement limit of $0.032 \mathrm{~mm}$. For the modified model, the strength was improved by about $1.72 \%$, and the displacement decreased by about $3.55 \%$ compared to the original model. Thus, the result can be used to assess the quality of the design, where no yielding and structural failure occurred in the firing load case, as having satisfied the requirement.
\end{abstract}

Keywords: Cylinder head; finite element; direct injection; compressed natural gas.

\section{INTRODUCTION}

Both the design and development of an automotive engine are complicated processes. To acquire the best performance and optimize the engine design in any operating condition, many analytical tools and experimental works are needed to find the optimum structure for the engine design (Lee, Chiang, Chen, \& Chen, 2005). In the automotive engine, the cylinder head structure is the most important component affecting the performance of a car and one of the heavily loaded combustion chamber components (Zhao, Lai, \& Harrington, 1999). All these components require careful attention especially during the assembly design in order to avoid any failed structure at engine operations (Lee et al., 2005). The cylinder head of a direct injection engine is highly influenced by the geometry of the combustion chamber injector location. In fact, a small change in geometry can lead to considerable changes in the mixture distribution 
and performance of the engine (Yadollahi \& Boroomand, 2013). With the increasing emphasis on the need to improve automotive fuel economy, automotive engineers are motivated to develop new engines to enhance fuel consumption and power and to reduce emissions (Yadollahi \& Boroomand, 2013; Zhao et al., 1999). In addition, due to the increasingly strict legal limits on emissions levels, the use of alternative fuels, including compressed natural gas (CNG), has increased along with the importance of developing alternative fuel technology. In the SI engine, direct injection (DI) technology significantly increases the engine volumetric efficiency and decreases the need to use the throttle valve for control purposes (Aziz, Rashid, Firmansyah, \& Shahzad, 2010; Yadollahi \& Boroomand, 2013; Zhao et al., 1999). All these technologies were developed to overcome the problems of using CNG especially in relation to the broad storage problem and reduced performance compared to gasoline (Durell, Allen, D., \& Heath, 2000; Gharehghani, Hosseini, \& Yusaf, 2013; Yusaf, Baker, Hamawand, \& Noor, 2013). However, with the design and development of the compressed natural gas direct injection (CNGDI) engine, both engine performance and reduced exhaust emissions may be further improved.

In engineering analysis, a theoretical and numerical model is the starting point for researchers to develop and design an engine component (Fadaei, Vafadar, \& Noorpoor, 2011). In addition, the application of finite element analysis (FEA) tools in engine development can reduce the risk and the testing effort in producing a prototype (Durell et al., 2000). Other than that, the combination of computational fluid dynamics and FEA analysis can also be performed to predict accurate stress/temperature distribution and thermo-mechanical cycles that can affect internal combustion engines under actual operating conditions (Fontanesi \& Giacopini, 2013). Zhang, Zuo, and Liu (2013) investigated the failure of a diesel engine cylinder head based on the finite element method. The ability to predict the design performance before it goes into production has become more important and relies on accurate computer models of all aspects of engine operation (Fadaei et al., 2011). Therefore, the commercial software, MSC Nastran/Patran, is employed to perform the stress and displacement analysis of the cylinder head structure for various engine speeds in the range 1000-5400 rpm. The gas pressure from the combustion chamber is used as a load into the cylinder head model, which is subjected to direct injected natural gas combustion pressure under various loading conditions. The results of this research can be used to develop a design procedure for a new CNGDI cylinder head engine.

\section{CYLINDER HEAD MODELING}

The original and modified CNGDI cylinder head materials used in this simulation are shown in Table 1. In this work, the material used for the original cylinder is aluminum alloy type AC4B, while the new cylinder head is aluminum alloy type A356-T6. However, for the simulation, both designs will use only the A356-T6 material. 
Table 1. Specification for the cylinder head material

\begin{tabular}{lcc}
\hline \multirow{2}{*}{ Material Properties } & \multicolumn{2}{c}{ Value } \\
& $\begin{array}{c}\text { AC4B (old } \\
\text { material) }\end{array}$ & $\begin{array}{c}\text { A356-T6 (new } \\
\text { material) }\end{array}$ \\
\hline Modulus of elasticity (MPa) & $71 \times 10^{3}$ & $72 \times 10^{3}$ \\
Compressive yield strength (MPa) & 166 & 172 \\
Tensile yield strength (MPa) & 159 & 164 \\
Poisson's ratio & 0.33 & 0.33 \\
Density $\left(\mathrm{kg} / \mathrm{m}^{3}\right)$ & 2740 & 2713 \\
\hline
\end{tabular}

The original and modified cylinder head models, as well as a cross-section area of the spark plug and injector are shown in Figure 1. The design specifications of the cylinder head are detailed in Table 2. This original model was modified to make retrofitting of gas injectors alongside the spark plug possible in the center of the combustion chamber, and was used for the 3D solid geometry modeling. Because of the complexity of the geometrical design, only a quarter or one-cylinder model was considered for analysis. With this new design configuration, the combustion process inside the cylinder will be more efficient and completely burned in order to achieve the best performance and reduce the exhaust emissions. Nowadays, most of the automotive cylinder head of the engine is made of aluminum alloy which, because of its higher thermal conductivity, generally operates about $30-80 \%$ cooler than the equivalent castiron, and is lighter than other materials.

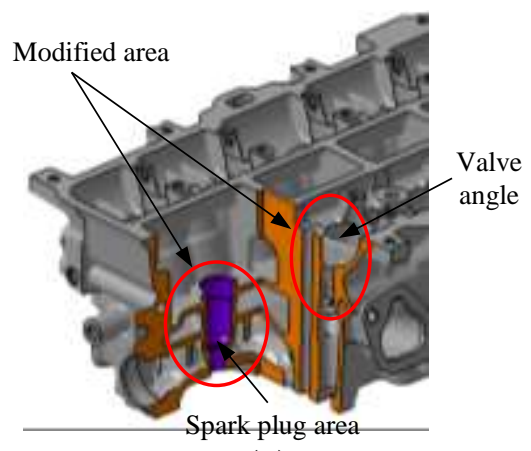

(a)

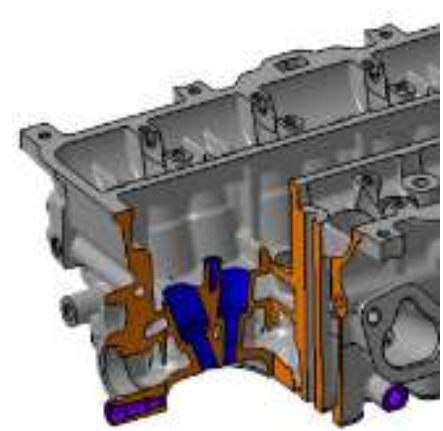

(b)

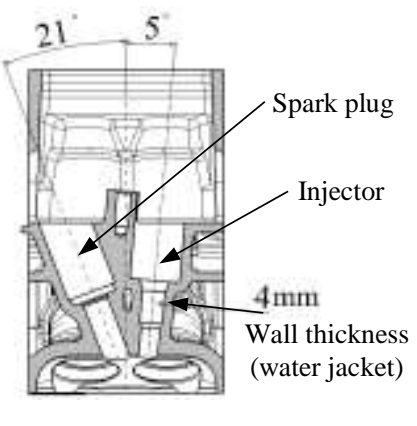

(c)

Figure 1. CAD model for cylinder head: (a) original model; (b) modified model (CNGDI); (c) cross-section area of spark plug and injector (modified model).

Table 2. Specification for the cylinder head model

\begin{tabular}{lcc}
\hline \multicolumn{1}{c}{ Specification } & \multicolumn{2}{c}{ Cylinder Head Design } \\
& Original & Modified (CNGDI) \\
\hline Cylinder height $(\mathrm{mm})$ & 134.7 & 136.7 \\
Intake valve angle $\left(^{\circ}\right)$ & 21.5 & 20.95 \\
Exhaust valve angle $\left(^{\circ}\right)$ & 20.5 & 20.05 \\
Spark plug angle $\left(^{\circ}\right)$ & 90 & 21 \\
Injector angle $\left(^{\circ}\right)$ & 34 (at intake manifold) & 5 (at center cylinder) \\
Wall thickness area water & 4 & 4 \\
jacket, minimum $(\mathrm{mm})$ & & 4 \\
\hline
\end{tabular}




\section{FINITE ELEMENT MODELS AND ANALYSIS PROCEDURE}

\section{Finite Element Model}

Finite element models of both cylinder heads used in the numerical analysis were generated in order to estimate the stress distribution and structural displacement. FEA will provide results that may be used to evaluate the strength of design based on the von Mises criterion and to identify areas that require improvement. The von Mises stress for a 3-dimensional case can be summarized as the following equation:

$$
\sigma_{v}=\sqrt{\frac{\left(\sigma_{1}-\sigma_{2}\right)^{2}+\left(\sigma_{2}-\sigma_{3}\right)^{2}+\left(\sigma_{3}-\sigma_{1}\right)^{2}}{2}}
$$

where $\sigma_{v}$ is von Mises stress, and $\sigma_{1}, \sigma_{2}$ and $\sigma_{3}$ are the principal stress in the loaded bodies. The design can be satisfied if the maximum von Mises stress obtained is below the yield strength of the material (Juvinall \& Marshek, 1991; Schaeffer, 2001).

For a good quality of mesh and results, some of the critical areas in the cylinder head were defined with higher order curves and surfaces. The shape around the deck of the combustion chamber that provides the location of the intake and exhaust valves, the spark plug and the injector were the areas of main concern and a finer mesh was used in these areas in order to get accurate stress distribution. Hence, a model of the modified cylinder head with 243,096 solid elements and 402,704 nodes was produced, as shown in Figure 2(b). The FEA was executed on HP Workstation xw6200 and interfaced with a high performance computer, the SGI Origin 300 (4 CPU). The CPU time required for a static run under single load was about 2 hours, while for an assembly load it was about 2.5 hours.

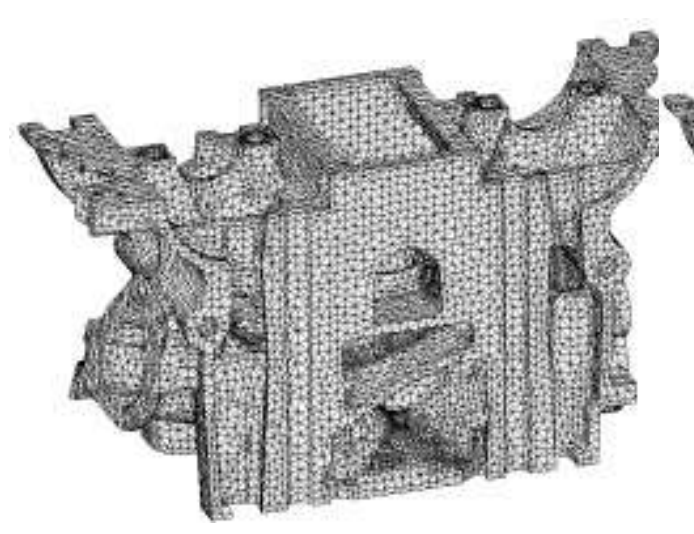

(a)

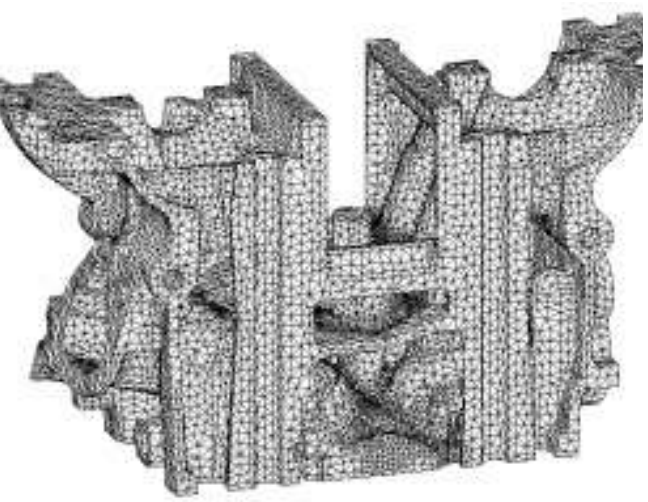

(b)

Figure 2. 3D solid element meshes in (a) original model; (b) modified model.

Before the simulation began, several assumptions were made with regard to modeling the cylinder head structure (Chyuan, 2000): (1) the four cylinder heads possess a structural symmetry in their entity, hence the second cylinder head was removed from the complete model in order to reduce the calculation time and allow simpler boundary conditions to be enforced; (2) the maximum gas pressure of the 
combustion process was used for the firing loading in the steady state condition. Besides that, the assembly model (see Figure 3 ) was also simulated in order to get a better result in terms of stress and displacement in the valve area, and to ensure that their values did not exceed the strength and displacement limit of the material used.

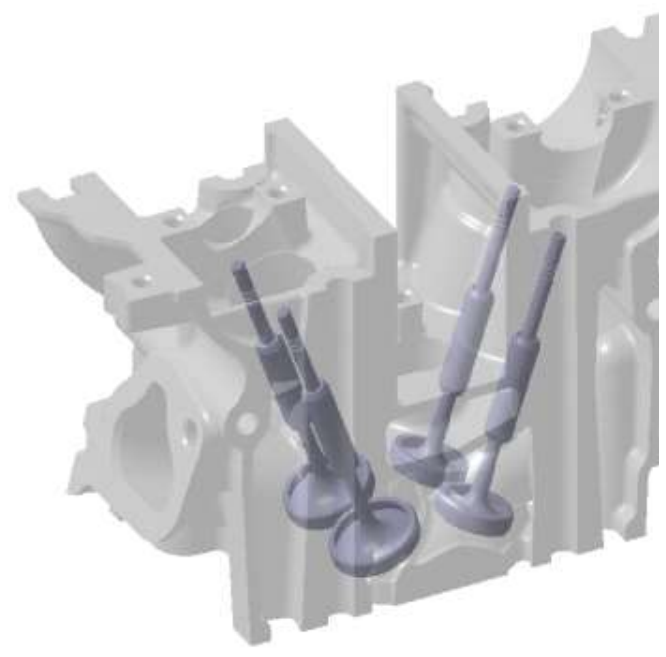

(a)

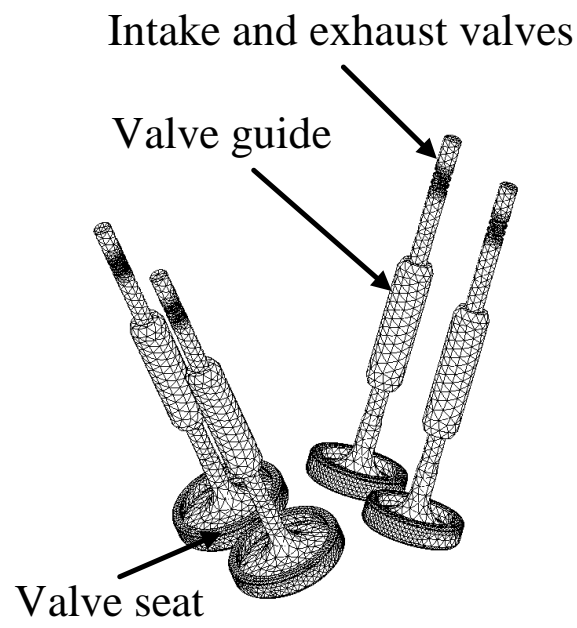

(b)

Figure 3. Assembly modeling: (a) assembly of sub components in cylinder head; (b) solid element mesh for valve guide, valve seat and valves.

\section{Analysis Procedure}

For structural analysis, pressure from the combustion process was used as a load for the analysis. The gas pressure that was produced from the ignition of spark plugs and fuel was imposed on the surface of the combustion chamber. However, the magnitude of the gas pressure varied with engine speeds. For steady-state analysis, the average gas pressure was inserted into the loading conditions for the numerical simulation. The maximum pressure load was $5.8 \mathrm{MPa}$ at $2000 \mathrm{rpm}$ which was close to the experimental results based on the single cylinder research engine (SCRE), as shown in Figure 4. The gas pressure varied according to the engine speed, and based on the experimental results, the pressure would increase with increasing engine speed, but for very high engine speeds around 6000-7000 rpm, the pressure was decreasing because of insufficient fresh air entering the engine for the combustion process. In order to decrease the complexity of the boundary conditions, the interactions between the cylinder head gasket, cylinder head bolts and cylinder block were not modeled. Constraints were set on the bolt of the cylinder head used to fix the cylinder head to the cylinder block, while the cutting section in the cylinder head was defined as a symmetry condition, as shown in Figure 5. 


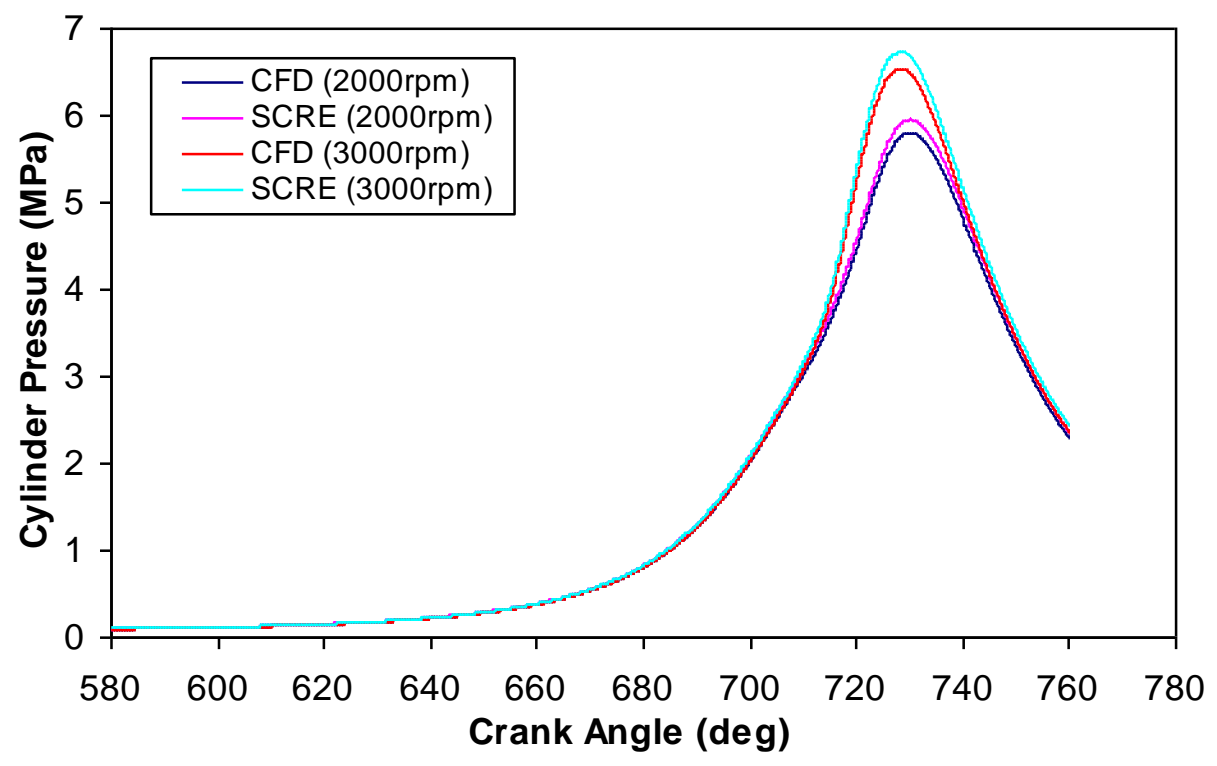

Figure 4. Gas pressure of CNGDI and SCRE engines at $2000 \mathrm{rpm}$ and $3000 \mathrm{rpm}$.

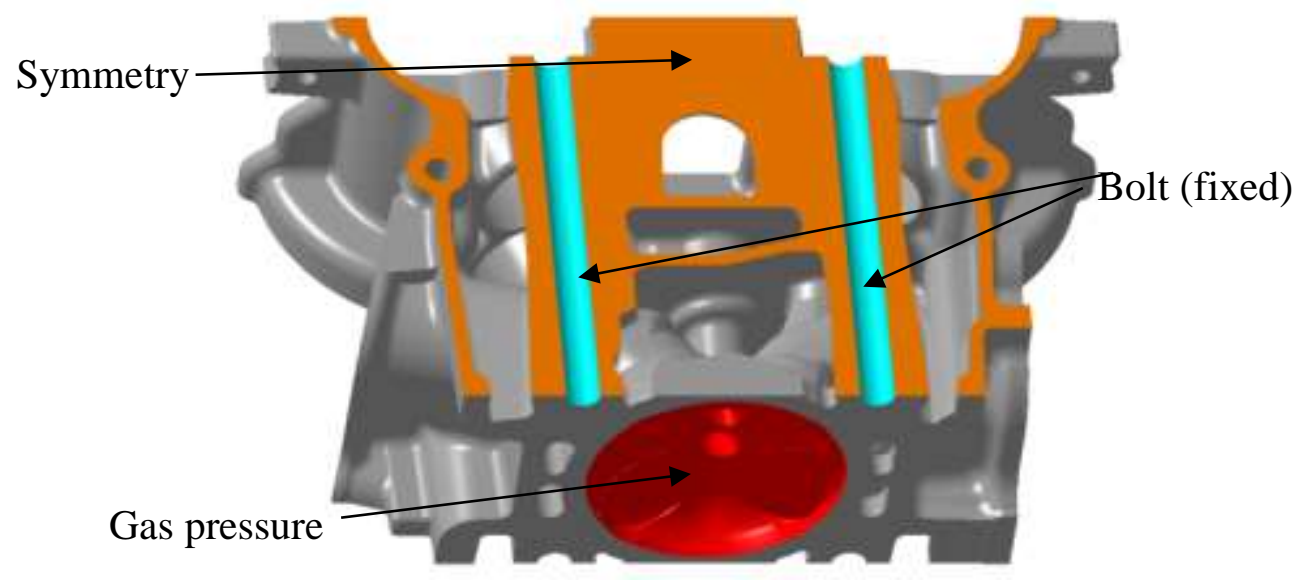

Figure 5. Boundary conditions for the cylinder head model

\section{RESULTS AND DISCUSSION}

\section{Stress and Displacement Analysis for Single Load Case}

FEA steady state predictions of stresses and displacement distributions in the cylinder head are shown in Figure 6 for an engine speed of $1000 \mathrm{rpm}$. The maximum stress for the modified cylinder head varies from $26.01 \mathrm{MPa}$ at $1000 \mathrm{rpm}$ to $39.84 \mathrm{MPa}$ at 5400 $\mathrm{rpm}$, while for the original cylinder head it varies from $26.47 \mathrm{MPa}$ at $1000 \mathrm{rpm}$ to 40.54 $\mathrm{MPa}$ at $5400 \mathrm{rpm}$, as the maximum gas pressure increases with increasing engine speed. The minimum von Mises stress is located at the areas between the cylinder head bolts and the top of cylinder head, which is due to local compressive loads. 


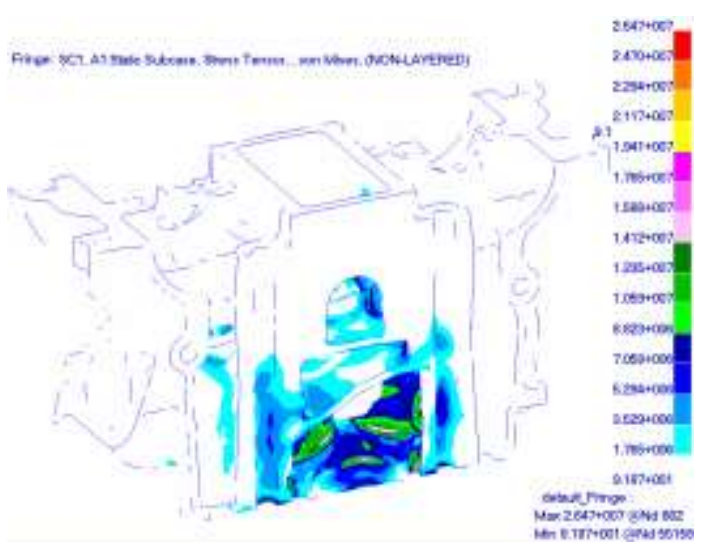

(a)

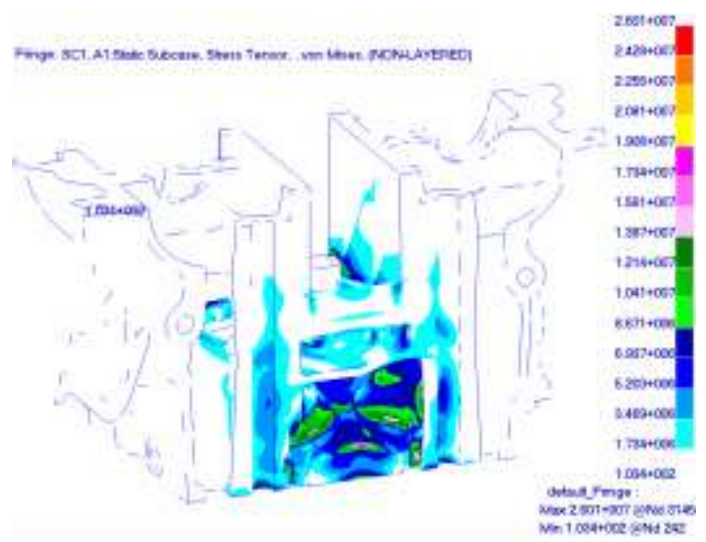

(b)

Figure 6. Stress distribution at 1000 rpm: (a) original design; (b) modified design.

The combustion chamber deck shows the largest displacement under gas pressure load, varying from $0.008465 \mathrm{~mm}$ at $1000 \mathrm{rpm}$ to $0.01296 \mathrm{~mm}$ at $5400 \mathrm{rpm}$, as shown in Figure 7. Due to the difference in size between the intake and exhaust valves, the distribution of these compressing stresses is slightly different between the inlet and exhaust sides of the cylinder head. From the results, the middle deck around the valve guides had been pushed up during the firing gas loads. Engineering experience suggests that this region is prone to structural failure due to the firing load if the detailed design or material properties are not correctly specified (Chyuan, 2000). The narrow bridge of the deck between the valve guide and the oil passage should be free of stress raisers on both sides, which can be achieved by using generous fillets. Besides, the surface finish in this area should be carefully investigated during the quality assurance procedure to ensure that porosity or sand insertions are avoided.

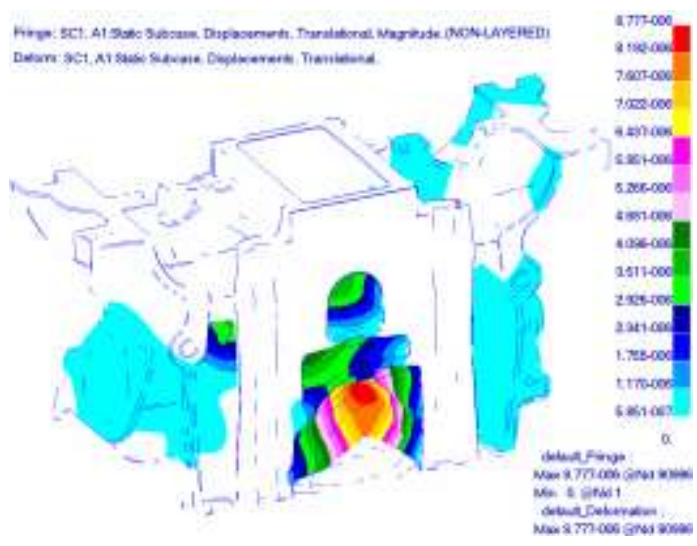

(a)

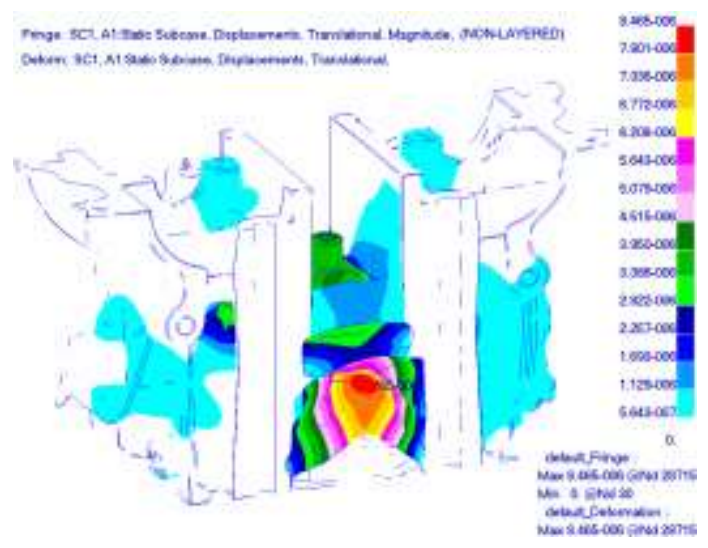

(b)

Figure 7. Displacement contours at 1000 rpm: (a) original design; (b) modified design.

In total, the design of the CNGDI cylinder head was improved by about $1.72 \%$ in terms of its stresses and by $3.56 \%$ in terms of the displacement, compared to the original design (see Figure 8). However, both designs are still below the compressive yield strength limit of $172 \mathrm{MPa}$. Hence, for the purpose of the base design, where the maximum von Mises stress for both designs does not exceed the material strength limit, 
the requirement for cylinder head design can be satisfied, with no yielding and structural failure under the firing load case. In terms of the safety factor, both of the cylinder head designs are safe and fulfilled the nominal safety factor for the base design, especially for the engine component. For the CNGDI cylinder head, the safety factor was about 4.32 compared to the original design of about 4.09. These safety factors were determined based on the maximum von Mises stress at $5400 \mathrm{rpm}$ and compressive yield strength, by using Eq. (2):

$$
N=\frac{S_{y}}{\sigma_{v}}
$$

where $N$ is the safety factor, $S_{y}$ is the yield strength and $\sigma_{v}$ is the von Mises stress.

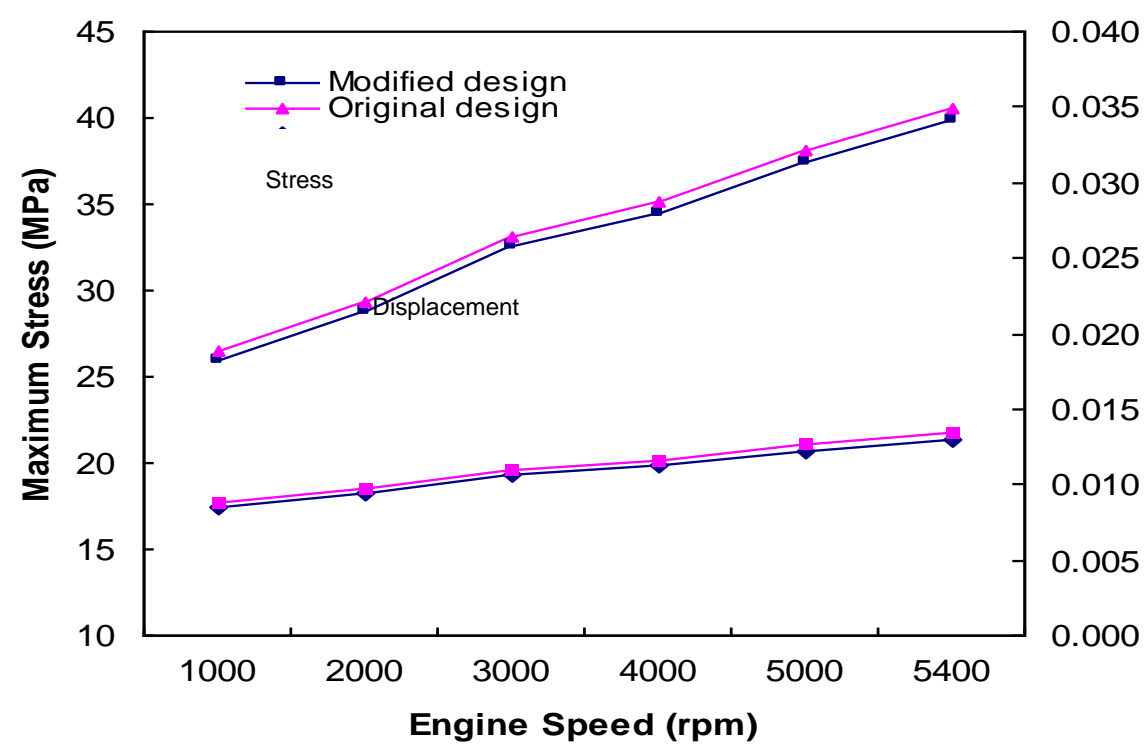

Figure 8. Maximum stress and displacement at several engine speeds.

\section{Stress and displacement analysis for assembly load case}

Under assembly loads on the cylinder head, valve seats and valve guides, the maximum von Mises stress value is $56.16 \mathrm{MPa}$ at $5400 \mathrm{rpm}$, located at the interface area between the valve seat and cylinder head deck because of local bending moment, as shown in Figure 9. Meanwhile, the maximum displacement distribution of the cylinder head is $0.00631 \mathrm{~mm}$ at $1000 \mathrm{rpm}$ and increases to $0.00972 \mathrm{~mm}$ at $5400 \mathrm{rpm}$. The pressure load in the cylinder head is equal but, in the area with maximum thickness, the pressure rise is larger and so is the stress. This is why high stress occurs in the valve bridge and near the valve seat. The result of the simulation shows higher stresses but lower displacement distribution in the cylinder head design with the assembling of valve guides and valve seats. For the engine speed of $5400 \mathrm{rpm}$, the difference in maximum stress can reach about $29.1 \%$, but the maximum displacement can fall by about $33.4 \%$ compared to the single load case. However, both of the designs are still below the material yield strength and displacement limits $(0.032 \mathrm{~mm}$ for valve guide, $0.045 \mathrm{~mm}$ for intake valve seat and $0.049 \mathrm{~mm}$ for exhaust valve seat), as shown in Figure 10. 


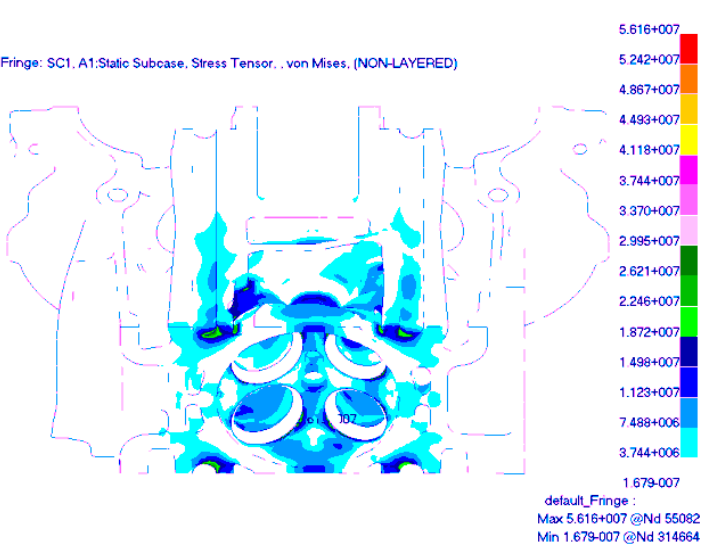

(a)

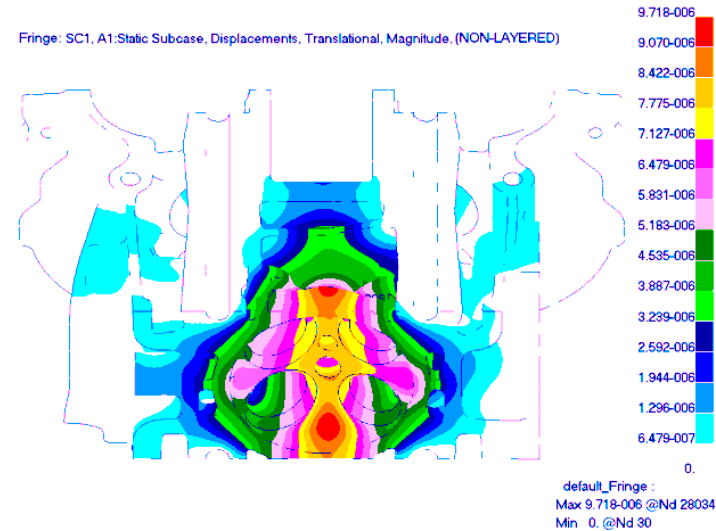

(b)

Figure 9. (a) Stress and (b) displacement contours at $5400 \mathrm{rpm}$ for modified design.

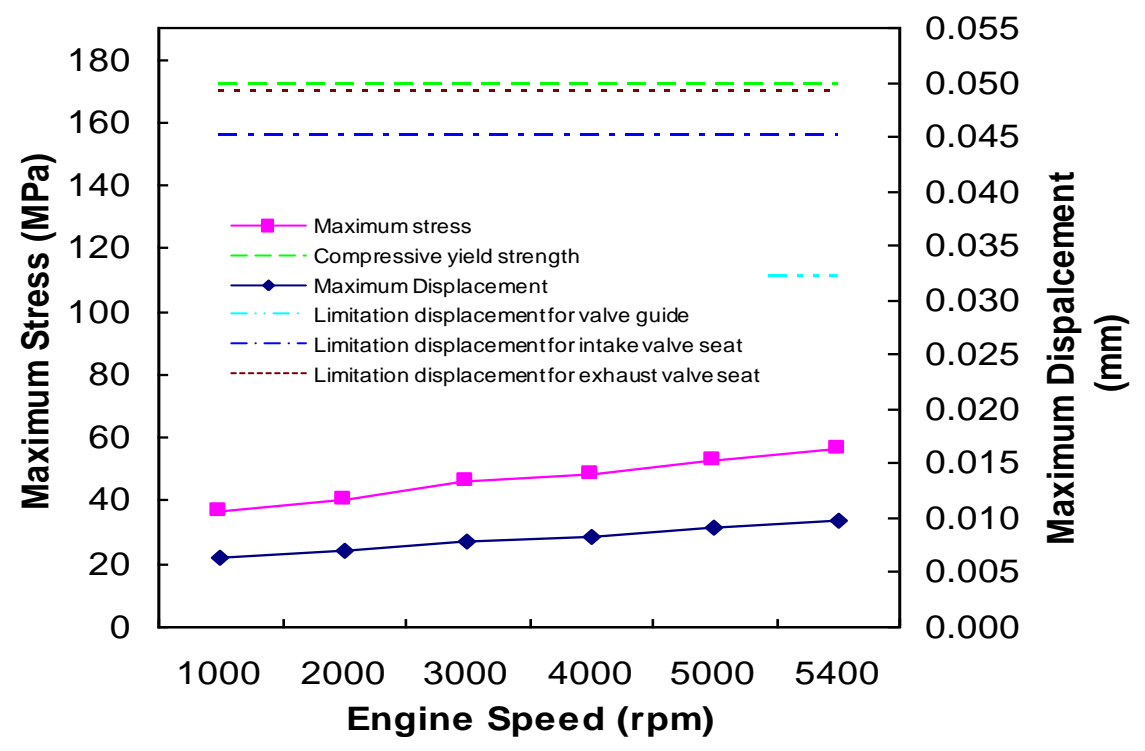

Figure 10. Maximum stress and displacement limits for cylinder head design.

\section{CONCLUSIONS}

In this paper, the structural analysis of a cylinder head model under gas firing loading for various engine speeds in the range 1000-5400 rpm were carried out by using FEA. For the CNGDI cylinder head, the structural analysis highlighted several areas of interest and the maximum stress in the new cylinder head was found not to exceed the allowable compressive yield strength of cylinder head design material, which is 172 $\mathrm{MPa}$, and was below the displacement limit of $0.035 \mathrm{~mm}$. Thus, the basic design criteria, which are to have no yielding or structural failure under the firing load case, are satisfied. In addition, the strength of the CNGDI cylinder head design was improved by about $1.72 \%$, and displacement was decreased by about $3.55 \%$ compared to the existing design. All these analyses can be used to help automotive engineers to design a more reliable cylinder head for a new engine. 


\section{ACKNOWLEDGMENTS}

The authors would like to thank the Malaysian Ministry of Science, Technology \& Innovation for sponsoring this work under project IRPA 03-02-02-0057-PR0030/10-04 and TF0608C073.

\section{REFERENCES}

Aziz, A., Rashid, A., Firmansyah, \& Shahzad, R. (2010). Combustion analysis of a cng direct injection spark ignition engine. International Journal of Automotive and Mechanical Engineering, 2, 157-170.

Chyuan, S. W. (2000). Finite element simulation of a twin-cam 16-valve cylinder structure. Finite Elements in Analysis and Design, 35, 199-212.

Durell, E., Allen, J., D., L., \& Heath, J. (2000). Installation and development injection system for a bi-fuel gasoline and compressed natural gas engine. Paper presented at the Proc. of 7th International Conference and Exhibition on Natural Gas Vehicles.

Fadaei, M., Vafadar, H., \& Noorpoor, A. (2011). New thermo-mechanical analysis of cylinder heads using a multi-field approach. Scientia Iranica B, 18(1), 66-74, .

Fontanesi, S., \& Giacopini, M. (2013). Multiphase cfd-cht optimization of the cooling jacket and fem analysis of the engine head of a v6 diesel engine. Applied Thermal Engineering, 52, 293-303.

Gharehghani, A., Hosseini, R., \& Yusaf, T. (2013). Investigation of the effect of additives to natural gas on heavy-duty si engine combustion characteristics. Journal of Mechanical Engineering and Sciences, 5, 677-687.

Juvinall, R. C., \& Marshek, K. M. (1991). Fundamentals of machine component design (2 ed.). New York: John Wiley \& Sons.

Lee, C. C., Chiang, K. N., Chen, W. K., \& Chen, R. S. (2005). Design and analysis of gasket sealing of cylinder head under engine operation conditions. Finite Elements in Analysis and Design, 41, 1160-1174.

Schaeffer, H. G. (2001). Msc/nastran primer for linear analysis (2 ed.). USA: MSC Software Corporation.

Yadollahi, B., \& Boroomand, M. (2013). The effect of combustion chamber geometry on injection and mixture preparation in a cng direct injection si engine. Fuel, 107, 52-62.

Yusaf, T., Baker, P., Hamawand, I., \& Noor, M. M. (2013). Effect of compressed natural gas mixing on the engine performance and emissions. International Journal of Automotive and Mechanical Engineering, 8, 1416-1429.

Zhang, Q., Zuo, Z., \& Liu, J. (2013). Failure analysis of a diesel engine cylinder head based on finite element method. Engineering Failure Analysis, 34, 51-58.

Zhao, F., Lai, M. C., \& Harrington, D. L. (1999). Automotive spark-ignited directinjection gasoline engines. Progress in Energy and Combustion Science, 25, 437-562. 